\title{
Entrainment and Its Dependency on Environmental Conditions and Convective Organization in Convection-Permitting Simulations
}

\author{
TOBiAs BECKER ${ }^{\mathrm{a}}$ AND CATHY HOHENEGGER ${ }^{\mathrm{a}}$ \\ ${ }^{a}$ Max Planck Institute for Meteorology, Hamburg, Germany
}

(Manuscript received 14 July 2020, in final form 13 November 2020)

\begin{abstract}
In this study, we estimate bulk entrainment rates for deep convection in convection-permitting simulations, conducted over the tropical Atlantic Ocean, encompassing parts of Africa and South America. We find that, even though entrainment rates decrease with height in all regions, they are, when averaging between 600 and $800 \mathrm{hPa}$, generally higher over land than over ocean. This is so because, over Amazonia, shallow convection causes an increase of bulk entrainment rates at lower levels and because, over West Africa, where entrainment rates are highest, convection is organized in squall lines. These squall lines are associated with strong mesoscale convergence, causing more intense updrafts and stronger turbulence generation in the vicinity of updrafts, increasing the entrainment rates. With the exception of West Africa, entrainment rates differ less across regions than across different environments within the regions. In contrast to what is usually assumed in convective parameterizations, entrainment rates increase with environmental humidity. Furthermore, over ocean, they increase with static stability, while over land, they decrease. In addition, confirming the results of a recent idealized study, entrainment rates increase with convective aggregation, except in regions dominated by squall lines, like over West Africa.
\end{abstract}

KEYWORDS: Tropics; Convection; Convective-scale processes; Entrainment; Squall lines; Convective parameterization

\section{Introduction}

Over the last decades, the progress in reducing key uncertainties in climate models, in particular in convective precipitation, has been frustratingly slow (e.g., Hawkins and Sutton 2011; Fiedler et al. 2020). One of the main reasons is that, because of the coarse resolution of typical climate models, moist convection must be parameterized, which can lead to substantial intermodel differences (e.g., Stevens and Bony 2013). Within convective parameterizations, one of the main sources of uncertainty is the entrainment rate (e.g., Knight et al. 2007; Collins et al. 2011). In many models, the concept of entrainment arises from a bulk approach: convection is modeled as a mass flux, whose properties are distinct from its environment. The entrainment rate usually defines the amount of environmental air that is mixed into the updraft over a certain height range. Thus, the entrainment rate directly affects the characteristics of the updraft, in particular its buoyancy and strength. In addition, the entrainment rate indirectly affects the environment. For example, gravity waves bind the static stability in the environment to the updraft temperature profile, which in turn depends on the entrainment rate (e.g., Bretherton and Smolarkiewicz 1989). Determining what factors control the entrainment rate is difficult, as it can potentially be controlled by a combination of many different factors. Here, we aim to identify those factors that entrainment rate is most sensitive to.

In previous work, large-eddy simulations (LES) have mostly been used to better understand which environmental properties control entrainment rate (reviewed by de Rooy et al. 2013),

Corresponding author: Tobias Becker, tobias.becker@ecmwf.int or to quantify the entrainment rate at the updraft or convective-system scale (e.g., Khairoutdinov and Randall 2006; Romps 2010; Dauhut et al. 2016, 2017). These simulations are usually run on small domains, with prescribed largescale conditions. Many LES studies have shown that entrainment rates are strong near the boundary layer, and decrease with height in the free troposphere (e.g., Lin and Arakawa 1997; Kuang and Bretherton 2006). Reasons are versatile: first, only those updrafts with weaker entrainment rates remain positively buoyant and grow deeper; second, updraft size increases with height, and larger updrafts are thought to have smaller entrainment rates (e.g., Morton et al. 1956); and third, updraft velocity increases with height, which is thought to imply that more vertical kinetic energy generation is needed to entrain environmental air into the updraft, resulting in lower entrainment rates (Gregory 2001). In addition, an updraft with higher vertical velocity has less time to interact with the environment while rising to a certain height, which thus is expected to lead to smaller entrainment rates (Neggers et al. 2002; Lu et al. 2016). With respect to environmental conditions, Böing et al. (2012) have shown in their idealized LES studies that entrainment rates decrease in a moister and more unstable troposphere, in association with deeper and stronger convection. However, these dependencies are weak compared to the decrease of entrainment rate with height, and the general shortcoming of all of these LES studies is that the small domain size does not allow for convection to properly organize.

Mesoscale convective organization has the power to significantly alter the characteristics of convection and the entrainment rate, and thus may mask the expected dependency of entrainment rate on environmental conditions. There is no consensus yet on the relationship between convective 
organization, or more specifically convective aggregation, and entrainment rate. Based on water tank experiments, entrainment rate is assumed to scale with the inverse updraft size (Morton et al. 1956; Turner 1963), and thus is believed to be smaller when convection is more aggregated (Siebesma 1996). In conflict with these findings, we found that, in idealized simulations with a convection-permitting radiative-convective equilibrium (RCE) model, the turbulence generation of nearby updrafts in case of aggregated convection causes higher entrainment rates, even though updraft dilution decreases because entrainment efficacy is reduced as the aggregated updrafts entrain air from their moist shell (Becker et al. 2018). The potential weakness of that study is that the results stem from an RCE approach, where boundary conditions are homogeneous, large-scale forcing is inexistent, and convection ends up aggregating into one blob, which is not the case in reality.

In this study, we will take advantage of the Next-generation Aircraft Remote Sensing for Validation (NARVAL) simulations (Klocke et al. 2017), which are convection-permitting simulations that were conducted on a large tropical domain, including parts of the Atlantic, Africa, and South America. We will use a bulk approach to analyze how bulk entrainment rates for deep convection differ across and within different regions, with a focus on how entrainment rates depend on environmental properties and on convective organization. In this context, we will investigate whether the RCE findings from Becker et al. (2018) are also relevant under more realistic and more diverse tropical conditions.

In section 2, we introduce our methods and model. In section 3, we discuss general large-scale differences in atmospheric and convective properties across the analyzed tropical regions. In section 4, we compare the RCE findings to entrainment rates over the West Atlantic. In section 5, we discuss differences in entrainment rates across the tropics, with a focus on environmental conditions (section 5a), convective aggregation (section $5 \mathrm{~b}$ ), and the diurnal cycle (section $5 \mathrm{c}$ ). This is followed by a summary and our conclusions in section 6 .

\section{Method and model}

To estimate bulk entrainment rates over different tropical regions, we use the convection-permitting NARVAL simulations, conducted by Klocke et al. (2017). These simulations were run with the model Icosahedral Nonhydrostatic (ICON) and cover the whole tropical Atlantic Ocean, as well as parts of Africa and South America, from $10^{\circ} \mathrm{S}$ to $20^{\circ} \mathrm{N}$ and from $68^{\circ} \mathrm{W}$ to $10^{\circ} \mathrm{E}$. The simulations were run on a triangular grid with $3.8 \mathrm{~km}$ edge length (corresponding to a $2.5 \mathrm{~km}$ grid spacing on a Cartesian grid). At this resolution, the main features of precipitation (location, spatial propagation, and diurnal cycle) are well captured, and do not substantially differ from simulations with hectometer-scale resolution or observations [see Figs. 8, 11 and 12 in Stevens et al. (2020)]. Even though the employed horizontal grid spacing allows us to omit parameterizations for subgrid-scale orography and convection, other parameterizations need to be retained: the Lin-type one-moment cloud microphysics scheme (Lin et al. 1983; Baldauf et al. 2011), a diagnostic cloud cover scheme (developed by Martin Köhler), the Raschendorfer turbulence scheme (Raschendorfer 2001) and the Rapid Radiation Transfer Model (RRTM) radiation scheme (Mlawer et al. 1997; Stevens et al. 2013). The simulations were run for December 2013 (December) and August 2016 (August), in support of the NARVAL-South flight campaigns (Klepp et al. 2015; Stevens et al. 2016). The NARVAL simulations were initialized daily at 0000 UTC from the atmospheric analysis of the European Centre for Medium-Range Weather Forecasts (ECMWF). Each simulation was run for $36 \mathrm{~h}$, nudged at the outer boundaries to the 3-hourly ECMWF analyses. Like in other studies (e.g., Senf et al. 2018), we analyze the last $24 \mathrm{~h}$ of each simulation, with 3-hourly output. In addition, higher-resolution (1.9 km edge length) simulations were performed in the region of the flight campaign, in the tropical West Atlantic, defined by $4^{\circ} \mathrm{S}-$ $18^{\circ} \mathrm{N}, 64^{\circ}-42^{\circ} \mathrm{W}$. Those simulations, which are coupled by two-way nesting to the outer-domain simulation, with an update frequency of $3 \mathrm{~h}$, are compared in section 4 to RCE results from Becker et al. (2018). In all other sections, the outer-domain simulations are analyzed.

To quantify bulk entrainment rate, a "radioactive tracer" was used in Becker et al. (2018), which was injected in the lowest model level, and slowly decayed in the atmosphere with an $e$-folding time scale of 4 days. Other studies have used slightly differently defined "radioactive tracers" (Couvreux et al. 2010; Romps and Kuang 2011) or a "purity tracer" (Romps 2010) to calculate entrainment rates. In the NARVAL simulations, no external tracers are available. Instead, similar to other studies (e.g., Del Genio and Wu 2010), we use frozen moist static energy as a tracer. In Becker et al. (2018), we have shown that frozen moist static energy leads to very similar bulk entrainment rates as those obtained with a radioactive tracer. However, frozen moist static energy is not conserved above the freezing level because frozen particles may precipitate. This source of frozen moist static energy is not accounted for. Thus, we limit all analysis in this paper to the lower troposphere, below the freezing level.

We define frozen moist static energy $(h)$ as

$$
h=c_{p} T+g z+L_{v} q_{v}-L_{i} q_{i},
$$

where $c_{p}$ is the isobaric specific heat capacity, $T$ is temperature, $g$ is gravity, $z$ is geopotential height, $L_{v}$ is the enthalpy of vaporization, $q_{v}$ is specific humidity, $L_{i}$ is the enthalpy of fusion, and $q_{i}$ is specific cloud ice content (representing all nonprecipitating ice phases). Note that below the freezing level, the contribution from ice to frozen moist static energy is negligible and one could have equivalently used moist static energy. In agreement with Becker et al. (2018), we calculate bulk entrainment rate as follows: first, we filter the 4D-field of frozen moist static energy for all updraft grid points, $h_{u}$. Updraft grid points are defined with a threshold on vertical velocity and cloud condensate $\left(w>1 \mathrm{~m} \mathrm{~s}^{-1}, q_{1}+q_{i}>0.01 \mathrm{~g} \mathrm{~kg}^{-1}\right)$. Second, we associate an environmental frozen moist static energy $h_{e}$ with every updraft grid point, by horizontally averaging over all nonupdraft grid points (where $w<1 \mathrm{~m} \mathrm{~s}^{-1}$ or $q_{1}+q_{i}<$ $0.01 \mathrm{~g} \mathrm{~kg}^{-1}$ ) located in a neighborhood of radius $10 \mathrm{~km}$ around 

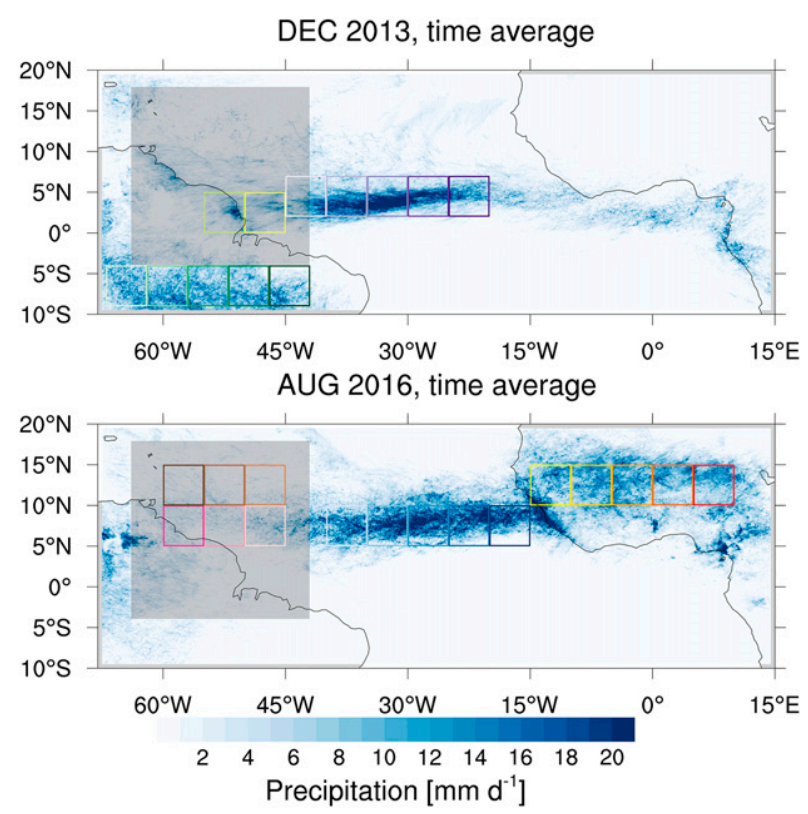

FIG. 1. Precipitation averaged over (top) December 2013 and (bottom) August 2016. The colored squares indicate the different analyzed regions: the two groups of purple and blue squares represent the Atlantic ITCZ region in December and August, green squares represent Amazonia (December), yellow-red squares represent West Africa (August), and the remaining group of eight squares (two in December, 6 in August) represent the West Atlantic. The last group of squares is in the nested domain with the locally refined grid $(1.9 \mathrm{~km}$ edge length), as illustrated by the gray shading.

each updraft grid point. Third, for each model level, we average $h_{u}$ and $h_{e}$ over space and time $\left(\hat{h}_{u}\right.$ and $\left.\hat{h}_{e}\right)$. While doing so, we also weight $h_{u}$ with the updraft mass flux, in accordance with Hohenegger and Bretherton (2011) and Becker et al. (2018). Finally, we calculate the entrainment rate $\epsilon$ following Betts (1975):

$$
\epsilon=\frac{-\partial_{z} \hat{h}_{u}}{\hat{h}_{u}-\hat{h}_{e}} .
$$

Bulk entrainment rates are calculated in five regions within the NARVAL domain. The regions are chosen in a way that they are dominated by precipitating deep convection (Fig. 1) and that their comparison allows an investigation of land-ocean differences, as well as differences with respect to the land type, Amazon or Sahel. The five regions are the West Atlantic (both August and December), the Atlantic ITCZ (December), the Atlantic ITCZ (August), Amazonia (December), and West Africa (August). The regions consist of at least five subdomains (size: $5^{\circ} \times 5^{\circ}$ ) each, represented in Fig. 1 by colored squares. This is motivated by the following considerations: First, in each geographical region, dividing into subdomains provides a sample of different realizations of the entrainment rate, which can be used to estimate uncertainties and variability. Second, the subdomains are large enough to get statistically significant estimates of entrainment rate, but small enough to ensure more homogeneous conditions than if the whole region were considered. And third, the small subdomain size enables us to select those $5^{\circ} \times 5^{\circ}$ squares where the majority of updraft grid points are associated with deep convection rather than shallow convection.

\section{How do large-scale characteristics affect deep convection in different tropical regions?}

Throughout the tropics, the characteristics of deep convective systems depend on the large-scale conditions they are embedded in. In this section we give a brief overview of the key characteristics of convection and its large-scale environment for the five considered regions, before investigating variations in entrainment rate in the next section. The NARVAL domain hosts squall lines over West Africa, organized deep convective clusters associated with the ITCZ over the central tropical Atlantic and, to a lesser degree, over the West Atlantic and Amazonia, as well as shallow convection in the surroundings. Figure 2 shows that, in terms of updraft area fraction, deep convection occurs the least frequently over the West Atlantic and the most frequently over the Atlantic ITCZ region, while Amazonia and West Africa lie in between. Figure 2 also shows that the average updraft velocities are remarkably similar in all regions except over West Africa, where updraft velocities are substantially higher.

In terms of large-scale environmental conditions, the marine boundary layer over the Atlantic is moister than over land, in particular in the Atlantic ITCZ region (Fig. 3). In this region, deep convective systems are ubiquitous, and cloud fraction as well as cloud liquid water content are the highest from the investigated regions. Over the West Atlantic, on the contrary, deep convection is the least active (Fig. 2), in agreement with free-tropospheric relative humidity, cloud fraction, and cloud liquid water being the lowest from the investigated regions (Fig. 3).

The different oceanic regions display a similar profile of static stability, as shown in Fig. 3 by the change of virtual potential temperature with height. Static stability is small in the boundary layer, meaning that convective inhibition (CIN) is small in contrast to the two regions over land (Table 1). In the free troposphere, static stability is smallest over West Africa and highest over the Atlantic ITCZ, reflected in the highest value of convective available potential energy (CAPE) over West Africa, and the smallest value of CAPE over the Atlantic ITCZ. Over Amazonia and the West Atlantic, CAPE is similar, even though the vertical profile of static stability differs significantly. Over Amazonia, static stability is lowest of all regions between 900 and $750 \mathrm{hPa}$, in association with a strong activity of shallow convection.

Over West Africa, the highest values of CAPE as compared to the other investigated regions (Table 1) are paired with the highest updraft velocities. However, as updraft buoyancies are the weakest (Fig. 4a), the high updraft velocities cannot be explained by buoyancy forcing alone. Instead, they are forced by a strong mesoscale convergence in the lower troposphere (Fig. 4b). In all regions except over West Africa, updraft 

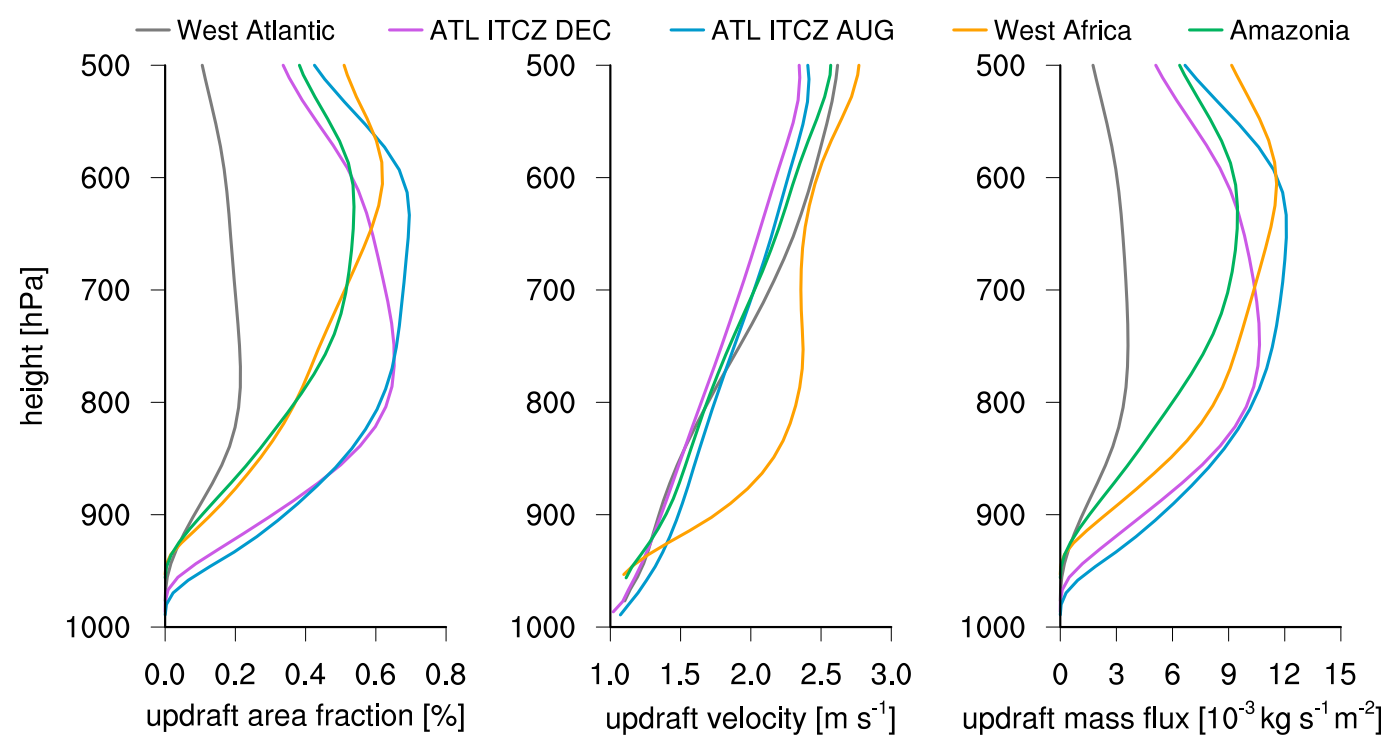

FIG. 2. Vertical profiles of (left) updraft area fraction, (center) updraft velocity, and (right) updraft mass flux, averaged over all updraft grid points (where $w>1 \mathrm{~m} \mathrm{~s}^{-1}$ and $q_{1}+q_{i}>0.01 \mathrm{~g} \mathrm{~kg}^{-1}$ ) in the respective regions within the NARVAL domain (Fig. 1).

velocity scales with updraft buoyancy (Fig. 5a). In contrast to this, a large fraction of convection is triggered dynamically over West Africa, which explains why a significant fraction of updrafts have negative buoyancies (Fig. 5b) and why updraft velocity may increase with increasingly negative updraft buoyancy (Fig. 5a). The dynamic forcing results from a very strong activity of squall lines, which propagate westward and also affect the convective activity in the Atlantic ITCZ region in August. As a consequence, in the Atlantic ITCZ region above $700 \mathrm{hPa}$, convective activity is stronger in August than in December, paired with a weaker static stability and a higher relative humidity (Fig. 3).

In summary, West Africa has the highest updraft velocities, the Atlantic ITCZ is very moist with very high cloud fraction and cloud liquid water content, the West Atlantic has rather suppressed conditions and in some respects, conditions over
Amazonia resemble those over the Atlantic more than those over West Africa.

\section{How do entrainment rates over the West Atlantic compare to entrainment rates in RCE simulations?}

Idealized model setups are very useful for process understanding, but a legitimate question is always to which extent the processes identified in the idealized frameworks are also relevant in the real world. In this section, we therefore compare the RCE entrainment rates from Becker et al. (2018) with entrainment rates derived over the West Atlantic. In this region, the grid spacing is locally refined (1.9 km edge length), and is thus comparable to the grid spacing in Becker et al. (2018) ( $1 \mathrm{~km}$ edge length). The West Atlantic region is particularly suitable for this comparison because its large-scale vertical
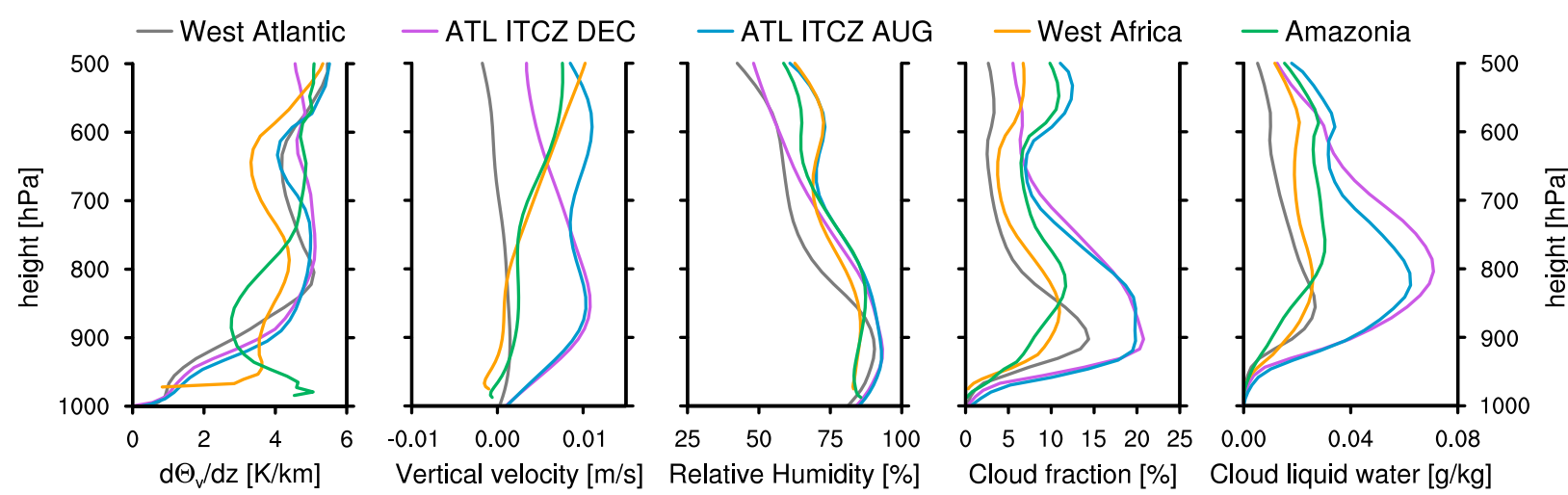

FIG. 3. Vertical profiles of (left to right) virtual potential temperature change with height (stability), vertical velocity, relative humidity, cloud fraction, and cloud liquid water averaged over the different tropical regions. 
TABLE 1. Convective available potential energy (CAPE) and convective inhibition (CIN) of a mean surface-layer parcel (Doswell and Rasmussen 1994) (in $\mathrm{J} \mathrm{kg}^{-1}$ ) as well as bulk entrainment rate $(\epsilon)$, vertically averaged from 800 to $600 \mathrm{hPa}\left(\right.$ in $\left.^{-1}\right)$. CAPE, CIN, and $\epsilon$ are averaged over the respective regions within the NARVAL domain (Fig. 1).

\begin{tabular}{lccc}
\hline \multicolumn{1}{c}{ Region } & CAPE & CIN & $\epsilon$ \\
\hline West Atlantic & 735 & 16 & $1.8 \times 10^{-4}$ \\
ATL ITCZ DEC & 550 & 7 & $2.0 \times 10^{-4}$ \\
ATL ITCZ AUG & 521 & 7 & $2.0 \times 10^{-4}$ \\
West Africa & 958 & 51 & $3.0 \times 10^{-4}$ \\
Amazonia & 728 & 32 & $2.4 \times 10^{-4}$ \\
\hline
\end{tabular}

velocity profile is close to zero (Fig. 3), resembling large-scale conditions in RCE.

To a first order, we find similar bulk entrainment rates over the West Atlantic and in the RCE simulations (Fig. 6). The main discrepancy is that entrainment rates are constant with height in RCE, while they decrease with height over the West Atlantic. Below $800 \mathrm{hPa}$, the entrainment rates are much larger over the West Atlantic than in the RCE simulations. This reflects the presence of much more active shallow convection over the West Atlantic than in the RCE simulations because shallow convection is associated with higher entrainment rates, as will be further discussed in the following. Over the West Atlantic, the freezing level is located between 600 and $550 \mathrm{hPa}$, and in the RCE simulations at $600 \mathrm{hPa}$. Between the freezing level and $800 \mathrm{hPa}$, updraft area fraction is relatively constant with height over the West Atlantic (Fig. 2), indicating that the majority of updrafts penetrate through these layers. From this characteristic we conclude that bulk entrainment rate estimates for deep convection are most reliable between 600 and $800 \mathrm{hPa}$, and thus we will limit all following entrainment rate analysis to this height range in the lower free troposphere.
Note that, since saturation vapor pressure strongly decreases with height, differences in specific humidity between updraft and environment can only be large in the lower troposphere. Thus, entrainment can only have a significant impact on updraft buoyancy in the lower troposphere. Between 600 and $800 \mathrm{hPa}$, the bulk entrainment rates in RCE are $1.5 \times 10^{-4} \mathrm{~m}^{-1}$ for unaggregated convection and $1.9 \times 10^{-4} \mathrm{~m}^{-1}$ for aggregated convection. Over the West Atlantic, the bulk entrainment rate $\left(1.4 \times 10^{-4} \mathrm{~m}^{-1}\right)$ is similar to $\mathrm{RCE}$ with unaggregated convection. With a coarser grid spacing $(3.8 \mathrm{~km}$ edge length), the bulk entrainment rate is higher $\left(1.8 \times 10^{-4} \mathrm{~m}^{-1}\right)$.

The main results from Becker et al. (2018) were that aggregated updrafts have higher entrainment rates than unaggregated updrafts (higher entrainment efficiency), but that buoyancy reduction weakens with aggregation because aggregated updrafts are surrounded by a shell of moist air (smaller entrainment efficacy). However, these RCE results stem from simulations with either completely aggregated or completely unaggregated convection, while in the NARVAL simulations, the atmosphere is usually in a state between aggregated and unaggregated convection. To distinguish between unaggregated and aggregated convection in the real world, we quantify the degree of convective aggregation based on updraft size, using the idea that wider (hereafter "larger") updrafts represent more aggregated convection, which we confirmed in Becker et al. (2018). To sample for updraft size, we count the number of horizontally connected updraft grid points. This method is used after nearest-neighbor remapping from the triangular ICON grid with a locally refined $1.9 \mathrm{~km}$ edge length (over the West Atlantic) to a Cartesian grid with approximately $1.4 \mathrm{~km}$ grid spacing. Grid points are considered connected if they share a border (so-called four connectivity). The updraft grid points are divided equally into three groups, "small," "medium," and "large", updrafts, according to
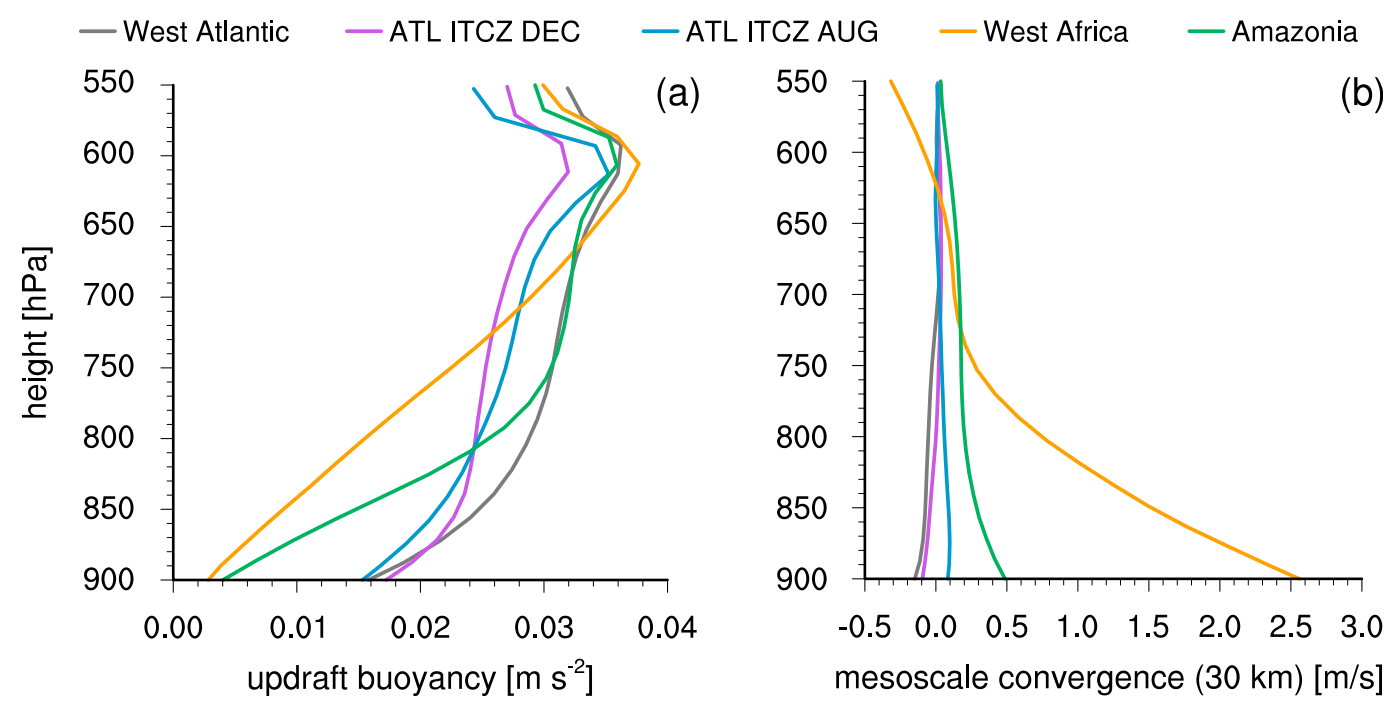

FIG. 4. Vertical profiles of (a) updraft buoyancy relative to the $10 \mathrm{~km}$ neighborhood and (b) mesoscale convergence in $30 \mathrm{~km}$ distance from each updraft grid point, averaged over the longitudinal and latitudinal direction, in the different tropical regions. 


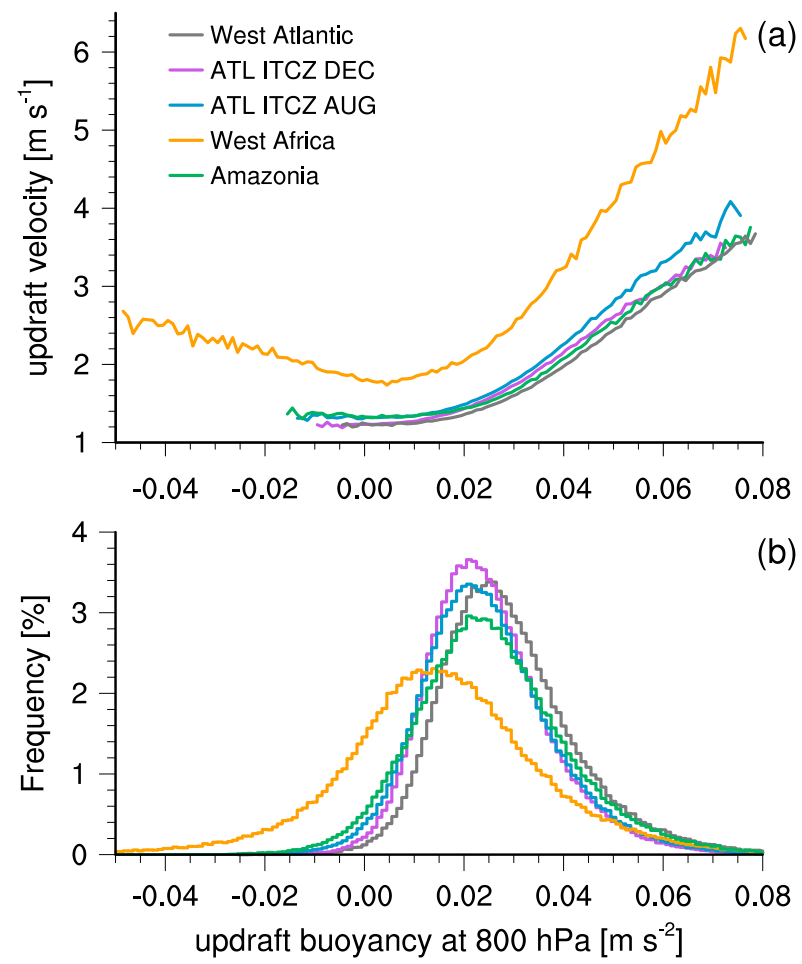

FIG. 5. (a) Updraft velocity vs updraft buoyancy, at $10^{-3} \mathrm{~m} \mathrm{~s}^{-2}$ intervals, showing only the values that are averaged over more than 100 updraft grid points. (b) Histograms of updraft buoyancy, with a bin size of $10^{-3} \mathrm{~m} \mathrm{~s}^{-2}$. In both panels results are shown for all variables at $800 \mathrm{hPa}$, and updraft buoyancy is calculated relative to the $10 \mathrm{~km}$ neighborhood. Results are shown for the different tropical regions.

the three terciles of the updraft size distribution in each subdomain.

Just like in RCE, the aggregated (large) updrafts over the West Atlantic have higher entrainment rates than unaggregated (small) updrafts (Fig. 7a). More precisely, large updrafts have $33 \%$ higher entrainment rates than small updrafts, especially noticeable in the two subdomains for December 2013. Nonetheless, updraft buoyancy reduction through entrainment stays approximately constant (Fig. 7b) because aggregated updrafts have a moister environment (Fig. 7c), and thus entrainment efficacy is reduced, in line with the RCE results in Becker et al. (2018). However, this effect is weaker than in the RCE simulations, in which the pronounced moist shell overcompensates the higher entrainment rates, resulting in a weaker updraft buoyancy reduction in case of aggregated convection. Note that our results do not show any significant dependency on resolution because, in the simulations with $3.8 \mathrm{~km}$ edge length, large updrafts have $21 \%$ higher entrainment rates than small updrafts in the subdomains over the West Atlantic (not shown).

As mentioned before, the NARVAL domain also hosts shallow convection. At kilometer-scale resolution, shallow convection is underresolved, with the consequence that its characteristics are significantly different compared to

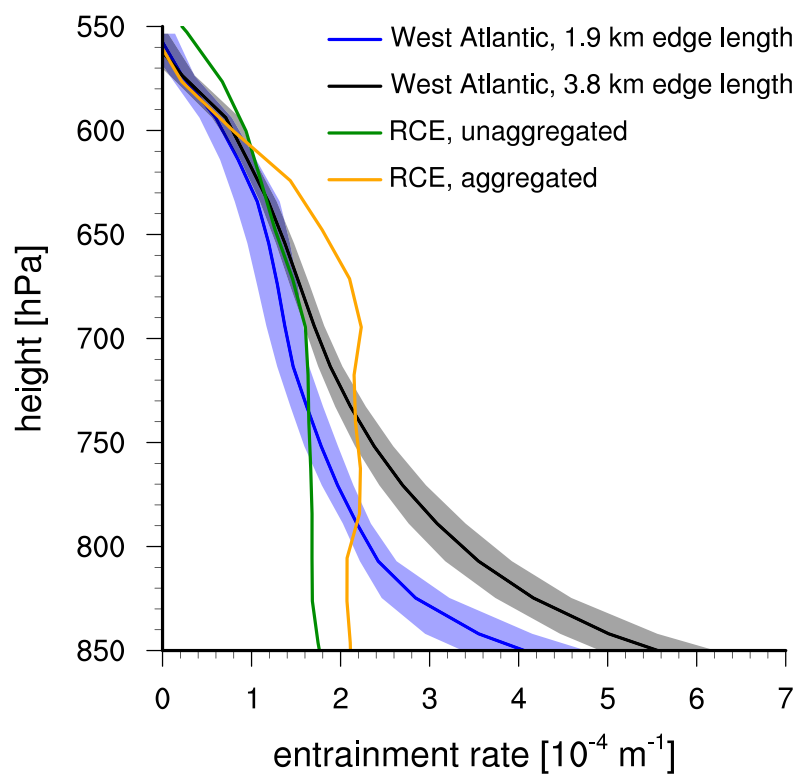

FIG. 6. Vertical profiles of bulk entrainment rates over the tropical West Atlantic in the NARVAL simulations (both with 1.9 and $3.8 \mathrm{~km}$ edge length). Estimates are calculated for each subdomain over the West Atlantic (Fig. 1) individually, and the average over all subdomains and one standard deviation range (shaded) are shown here. For comparison, bulk entrainment rates in RCE simulations with $1 \mathrm{~km}$ grid spacing (Becker et al. 2018) are shown as well. All entrainment rate estimates are based on frozen moist static energy as a conserved variable.

simulations at hectometer-scale resolution (Stevens et al. 2020). To check whether our entrainment rate estimates for deep convection are affected by the presence of shallow convection, we now only consider those updraft grid points where there is an updraft at $550 \mathrm{hPa}$ as well. As the updraft might be tilted, we relax this condition to updrafts within a $10 \mathrm{~km}$ neighborhood. When using this approach to subsample for deep convection, only $\sim 15 \%$ of the updraft grid points remain at $800 \mathrm{hPa}$. The entrainment rate decreases less strongly with height, while the average value (between 600 and $800 \mathrm{hPa}$ ) increases to $1.7 \times 10^{-4} \mathrm{~m}^{-1}$. However, this does not change the dependency on updraft size. Larger updrafts still have higher entrainment rates.

All in all, we were able to reproduce the findings from a previous RCE study (Becker et al. 2018) over the West Atlantic, even though dependencies are quantitatively weaker than in RCE. We find that aggregated updrafts have higher entrainment rates than unaggregated updrafts. However, aggregated updrafts are also surrounded by a moister environment, compensating for the higher entrainment rates and leading to a similar buoyancy reduction as in unaggregated updrafts.

\section{How do entrainment rates differ across the tropics?}

We have shown in the last section that, to a first order, bulk entrainment rates and their dependence on convective aggregation are similar over the West Atlantic and in RCE 

AUG, $55-60 \mathrm{~W}, 10-15 \mathrm{~N}$
AUG, $50-55 \mathrm{~W}, 10-15 \mathrm{~N}$
AUG, $45-50 \mathrm{~W}, 10-15 \mathrm{~N}$
AUG, 55-60 W, 5-10 N
AUG, $50-55 \mathrm{~W}, 5-10 \mathrm{~N}$
AUG, 45-50 W, 5-10 N
DEC, $50-55 \mathrm{~W}, 0-5 \mathrm{~N}$
DEC, $45-50 \mathrm{~W}, 0-5 \mathrm{~N}$
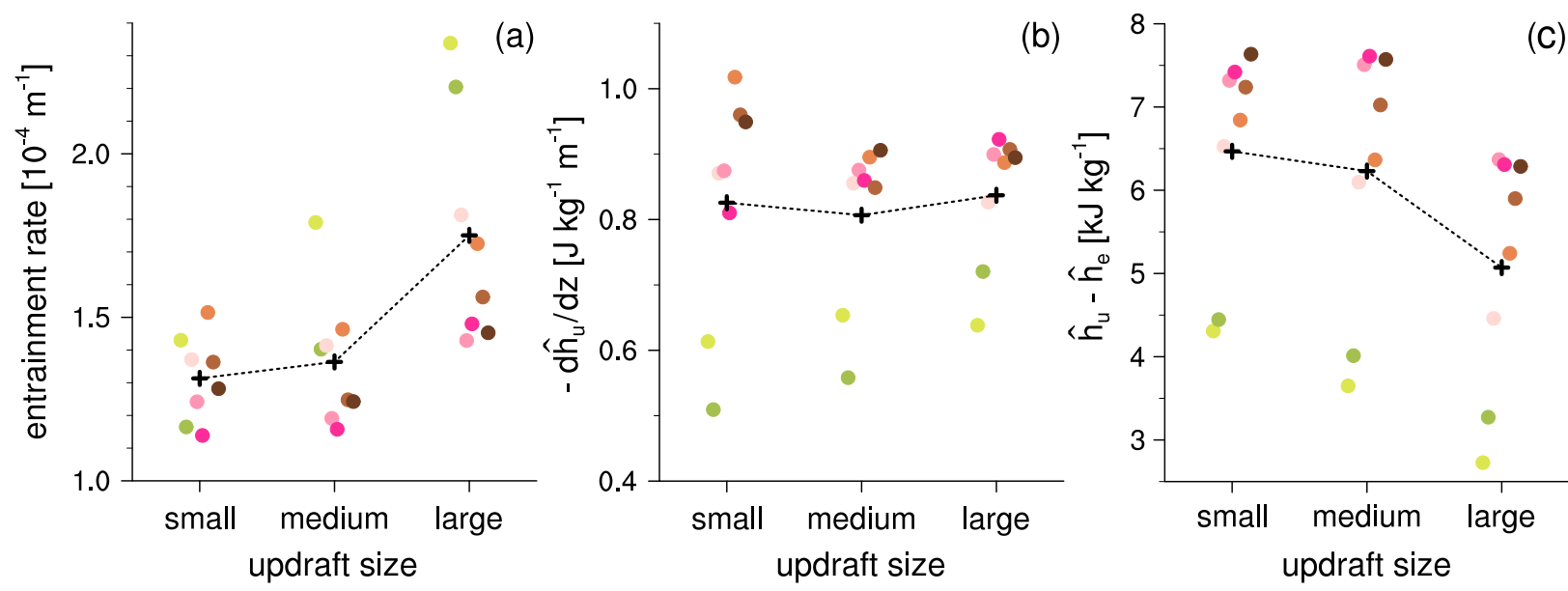

FIG. 7. (a) Vertical averages (600-800 hPa) of bulk entrainment rates, (b) change of updraft frozen moist static energy with height, and (c) frozen moist static energy difference between updraft and $10 \mathrm{~km}$ neighborhood, in all subdomains over the tropical West Atlantic (with $1.9 \mathrm{~km}$ edge length). Results are ordered by updraft size, where "small," "medium," and "large" correspond to the first, second, and third tercile of the updraft size distribution. The black crosses represent the mean value, averaged over all subdomains for each updraft size category.

simulations. In this section, we investigate how bulk entrainment rates differ across the tropics, and how entrainment rates depend on the environment that convection is embedded in (section 5a), convective aggregation (section 5b), and the diurnal cycle (section 5c).

\section{a. Dependence on environmental conditions}

In the NARVAL simulations, entrainment rates are higher over land (West Africa and Amazonia) than over ocean (Atlantic ITCZ and West Atlantic; now using $3.8 \mathrm{~km}$ edge length for a better comparability), as illustrated both in Fig. 8 and Table 1. Over land, the entrainment rates are the highest over West Africa, whereas over the three oceanic domains, the entrainment rates are more similar. Entrainment rates decrease with height in all regions except over West Africa below $800 \mathrm{hPa}$, where bulk entrainment rate estimates are artificially reduced because updrafts that start at higher levels have higher frozen moist static energies than the updrafts starting below. This happens because one of the main assumptions of the bulk approach, that the majority of updrafts penetrate through the analyzed layer, is not fulfilled below $800 \mathrm{hPa}$ anymore. Differences in entrainment rate across the regions could either reflect the sampling of different convective phenomena, for example deep versus shallow convection, or reflect different environmental conditions, for example in terms of static stability and environmental humidity, two atmospheric properties that are often mentioned to control the entrainment rate (e.g., Böing et al. 2012). These different options are investigated in the following.

The influence of shallow convection on the bulk entrainment rate estimates can be investigated by subsampling for deep convection, using the method introduced in section 4. Over
West Africa, this method does not work properly because, even above $800 \mathrm{hPa}$, the aforementioned assumption of the bulk approach, that the majority of updrafts penetrate through the analyzed layer, is not fulfilled anymore, and bulk entrainment rate estimates are artificially decreased. In the other regions, the average bulk entrainment rate (between 600 and $800 \mathrm{hPa}$ ) increases to $2.1-2.2 \times 10^{-4} \mathrm{~m}^{-1}$ over the ocean regions and to $2.5 \times 10^{-4} \mathrm{~m}^{-1}$ over Amazonia. Hence, compared

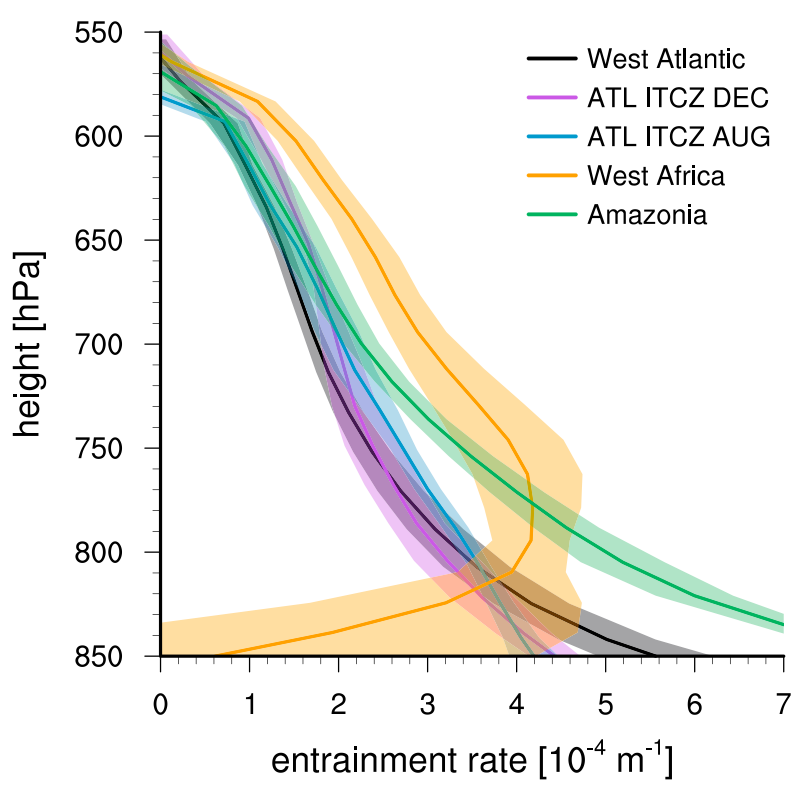

FIG. 8. Vertical profiles of bulk entrainment rates, computed as in Fig. 6, but for the different tropical regions (with $3.8 \mathrm{~km}$ edge length). 

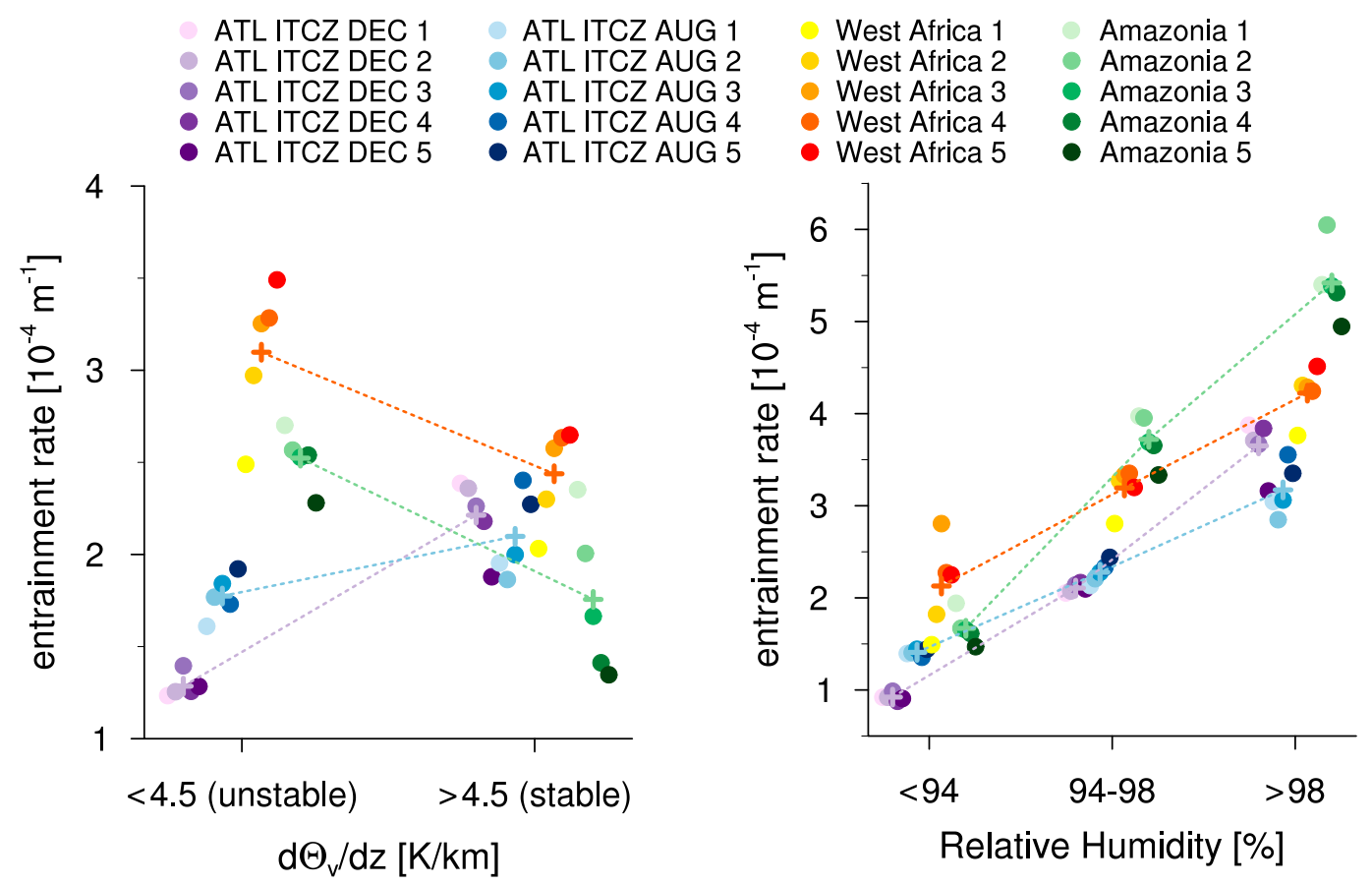

FIG. 9. Vertical averages $(600-800 \mathrm{hPa})$ of bulk entrainment rates, ordered by (left) static stability and (right) relative humidity (both averaged over the $10 \mathrm{~km}$ neighborhood of each updraft), in the different tropical regions. Subdomains are numbered from west to east. The crosses represent the mean value, averaged over all subdomains for each region and environmental condition.

to Table 1 , the entrainment rates in the different regions become slightly more similar, which is a result of smaller entrainment rates below $700 \mathrm{hPa}$ over Amazonia compared to when not subsampling for deep convection. The increase in similarity indicates that below $700 \mathrm{hPa}$, the higher entrainment rates over Amazonia compared to over ocean (Fig. 8) are, at least to some degree, related to differences in shallow convection. More specifically, the higher entrainment rates over Amazonia can stem from shallow convection being more frequent, being more efficient in entraining environmental air, or growing deeper than over ocean. The latter would be in line with small static stabilities between 750 and $900 \mathrm{hPa}$ (Fig. 3, discussed in section 3).

In terms of static stability, low (unstable) static stability has been shown to be associated with deeper and stronger convection and with a slightly smaller entrainment rate in idealized LES studies (Böing et al. 2012). In the NARVAL simulations, unstable environments are only associated with smaller entrainment rates over ocean, while the dependency over land is opposite (Fig. 9).

In terms of environmental humidity, it can be easily understood that in moist environments, updrafts are stronger and grow deeper because entrainment efficacy is smaller, so the same amount of entrainment causes a smaller reduction of updraft buoyancy (e.g., Derbyshire et al. 2004). However, this does not say anything about the actual dependency of entrainment rate on environmental humidity. In their LES study, Böing et al. (2012) have shown that environmental humidity and entrainment rate are weakly negatively correlated, consistent with other studies (e.g., Derbyshire et al. 2011), while some observations indicate a positive correlation ( $\mathrm{Lu}$ et al. 2018). In Bechtold et al. (2008), entrainment rate is parameterized to increase in a dry environment, and this change to the convective parameterization has been shown to increase the overall performance of the IFS model. In all NARVAL regions, the opposite is actually true, i.e., a dry environment is associated with low bulk entrainment rates (Fig. 9). One could argue that this strong positive correlation between entrainment rate and relative humidity is an artifact of our bulk approach: a dry environment means that $\hat{h}_{u}-\hat{h}_{e}$, the denominator in Eq. (2), increases. On the other hand, convective parameterizations use a bulk approach as well, and might suffer from similar problems. One could also argue that the buoyancysorting effect, which only allows for a biased selection of data points to show up in the updraft (e.g., Taylor and Baker 1991; de Rooy et al. 2013), explains why a dry environment is associated with small bulk entrainment rates: only the most buoyant updrafts survive in a dry environment, which means that $\hat{h}_{u}$ in the level above is biased toward high values, decreasing the bulk entrainment rate. Thus, based on the theoretical concept of buoyancy sorting, bulk entrainment rates are indeed expected to increase with environmental humidity.

Can the differences in environmental conditions explain the differences in entrainment rates across the regions and especially the much higher entrainment rates over West Africa? The significantly higher entrainment rates over West Africa cannot be explained by the dependency of entrainment rate on environmental humidity because humidity over West Africa 

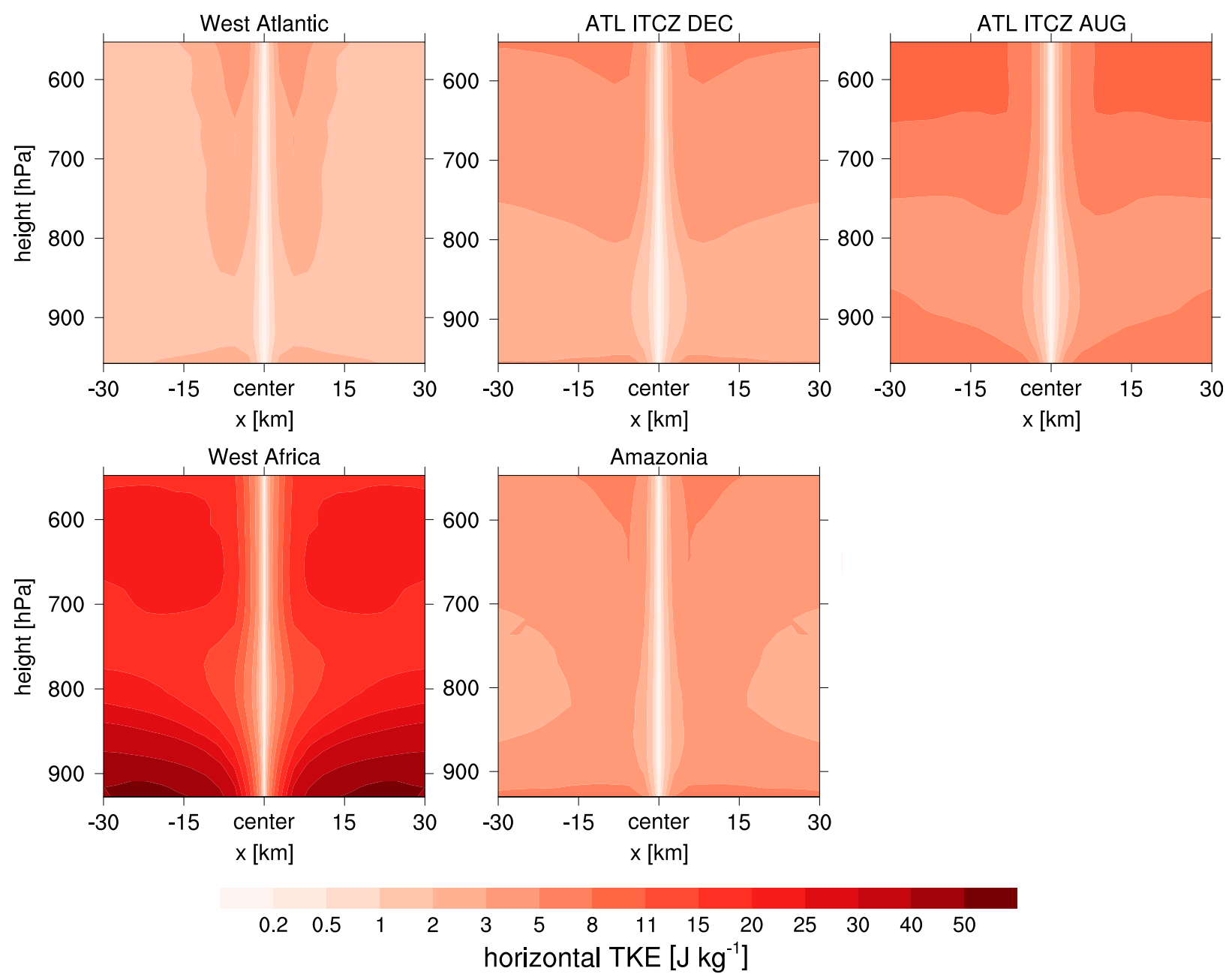

FIG. 10. Cross sections of average horizontal turbulence kinetic energy (TKE) in a specific zonal distance $(x)$ to each updraft (marked as “center"), within the central $5^{\circ} \times 5^{\circ}$ subdomains of the different regions. Horizontal TKE is calculated as in Becker et al. (2018) [see their Eqs. (2) and (3)], including a subtraction of the kinetic energy of the mean flow and mirroring the field to remove transient motion. As a consequence, horizontal TKE is zero at the "center."

strongly resembles humidity over the Atlantic ITCZ region, both on the large-scale (Fig. 3), and with respect to the $10 \mathrm{~km}$ neighborhood (not shown). The other discussed environmental property, free-tropospheric static stability, is low over West Africa (Fig. 3). At least in that region, it is in line with higher entrainment rates, but the dependency between stability and entrainment rate is inconclusive across regions (Fig. 9). Moreover, from Gregory (2001), who proposed to relate entrainment rate to buoyancy and inversely to the squared updraft velocity, small entrainment rates would be expected over West Africa given the high updraft velocities and small buoyancy. Thus, none of the discussed dependencies on environmental conditions are able to give a convincing explanation why entrainment rates are significantly higher over West Africa than over the other regions.

Instead, the high entrainment rates over West Africa are more dependent on the form of convective organization that dominates in this region, i.e., dynamically forced squall lines.
They are associated with strong mesoscale convergence, and the high updraft velocities generate strong turbulence, also because the squall lines are very large and aggregated. This is illustrated in Fig. 10, which shows the horizontal turbulence kinetic energy (TKE) in the vicinity of the updrafts, calculated in analogy to Becker et al. (2018). Over West Africa, horizontal TKE is more than twice as high as in the region with the second highest value of horizontal TKE, the Atlantic ITCZ in August. Note that this region is also affected by squall-line activity.

In summary, we find that across the NARVAL simulations, the higher entrainment rates over land compared to over ocean are at least to some extent related to both a stronger activity of shallow convection (over Amazonia), and, in the case of West Africa, to a stronger turbulence generation associated with squall lines. In addition, entrainment rates increase with static stability over ocean and decrease with static stability over land, while in all regions entrainment rates increase with environmental humidity. 
TABLE 2. Number of connected updraft grid points for the first, second, and third terciles of the updraft size distribution at $700 \mathrm{hPa}$, averaged over the respective regions within the NARVAL domain (Fig. 1).

\begin{tabular}{lccr}
\hline \hline \multirow{2}{*}{ Region } & \multicolumn{3}{c}{ Tercile } \\
\cline { 2 - 4 } & First & Second & Third \\
\hline West Atlantic & 3 & 9 & 23 \\
ATL ITCZ DEC & 5 & 12 & 29 \\
ATL ITCZ AUG & 5 & 16 & 50 \\
West Africa & 7 & 49 & 241 \\
Amazonia & 4 & 11 & 33 \\
\hline
\end{tabular}

\section{b. Dependence on convective aggregation}

In this section, we investigate whether the dependency of entrainment rate on convective aggregation, as found over the West Atlantic and in RCE simulations (Becker et al. 2018), is visible over the remaining regions and could explain differences in entrainment rates across regions. Again, we measure convective aggregation based on updraft size, in accordance with section 4 . Table 2 lists the mean values for the three terciles of the updraft size distribution in the different regions, showing that convection is the least aggregated over the West Atlantic, and the most aggregated over West Africa. Likewise, entrainment rates are smallest over the West Atlantic, and highest over West Africa (Table 1). Hence, generally speaking, regions with more aggregated convection have higher entrainment rates, in line with the RCE findings from Becker et al. (2018).

However, within the individual regions, the dependency of entrainment rate on convective aggregation is not always in line with Becker et al. (2018) and our previous findings over the West Atlantic (section 4). Even though, in accordance with expectations, entrainment rates increase with updraft size over Amazonia and over the December Atlantic ITCZ region, they slightly decrease with updraft size over the August Atlantic ITCZ region, and strongly decrease over West Africa (Fig. 11a).

In Becker et al. (2018), we have shown that aggregated updrafts have higher entrainment rates because horizontal TKE strongly increases when convection aggregates. Here we also find an increase of horizontal TKE (measured as in Fig. 10) with aggregation in all regions, even over West Africa, but the relative increase of horizontal TKE with updraft size is less strong than in RCE. Instead of a sixfold increase with aggregation in RCE, the NARVAL regions show on average a doubling of horizontal TKE for large updrafts relative to small updrafts, with the strongest relative increase (a tripling) over West Africa. Thus, even though high values of horizontal TKE may be one explanation why entrainment rates are generally high over West Africa (section 5a), this metric cannot explain why entrainment rates decrease with aggregation over West Africa and over the August Atlantic ITCZ.

Instead, the differences in mesoscale organization throughout the regions can explain the distinct dependency of entrainment rates on updraft size. Over West Africa, convection is characterized by squall lines: medium and large updrafts consist of squall lines entirely, while small updrafts consist both of nonconnected fragments of squall lines, and of any other kind of convection. Thus, unlike in RCE and in most of the other regions, updraft size does not quantify the size of individual updrafts in a classical sense, but rather the length of squall lines, which can be hundreds of kilometers long. As squall lines are forced by a strong mesoscale convergence, they are associated with very high updraft velocities, in particular for large updraft sizes (Fig. 12). The strong mesoscale convergence, which dominates any thermodynamic response, is also the reason why updraft velocity does not scale with updraft buoyancy over West Africa (Fig. 5a), as already discussed in section 3. Thus, even though below $750 \mathrm{hPa}$, updrafts over West Africa are the least buoyant from all the investigated regions (Figs. 4a and 12a), large updrafts (long squall lines) have very high updraft velocities at $750 \mathrm{hPa}$ (Fig. 12c), in association with a very strong mesoscale convergence (Fig. 12b). Thus, the decrease of entrainment rate with updraft size over West Africa is in line with the Gregory parameterization (Gregory 2001), which assumes that a high updraft velocity and a low updraft buoyancy leads to a low entrainment rate.

Squall lines that form over West Africa propagate westward, which explains why convection over the August Atlantic ITCZ region tends to show the same characteristics as over West Africa (though to a lesser extent). For example, updraft sizes are higher than in the other regions, particularly for large updrafts (Table 2), and the entrainment rate slightly decreases with updraft size (Fig. 11a).

Updraft buoyancy reduction through entrainment is almost independent of convective aggregation over the Atlantic ITCZ and Amazonia (Fig. 11b), which is in line with the findings over the West Atlantic. The largest updrafts have the smallest value of $\hat{h}_{u}-\hat{h}_{e}$ (Fig. 11c), indicating a significant intensification of the moist shell and a decrease of entrainment efficacy, in particular over Amazonia, but also over the December Atlantic ITCZ region. Over West Africa, the moist shell does not intensify from medium to large updrafts, which is another indication that convection that organizes in squall lines has substantially different characteristics than convection that organizes in RCE.

In summary, our earlier RCE findings (Becker et al. 2018), which demonstrated that the entrainment rate increases as convection becomes more aggregated, do not hold true in all tropical regions studied here. Results can be reproduced in those regions where the dynamic and thermodynamic conditions resemble those in RCE, over the West Atlantic, the December Atlantic ITCZ and Amazonia, while we find the opposite relationship between updraft size and entrainment rate in those regions that are dominated by squall-line activity, in particular over West Africa.

\section{c. Dependence on the diurnal cycle}

In general circulation models, a too weak entrainment rate can be responsible for convective precipitation peaking too early during the day over land compared to observations, as a few studies have already shown (e.g., Del Genio and Wu 2010). A solution would be an entrainment rate that is variable in space and time, high in the morning and low in the afternoon 


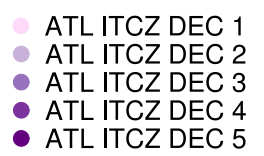

ATL ITCZ AUG 1

ATL ITCZ AUG 2

- ATL ITCZ AUG 3

- ATL ITCZ AUG 4

- ATL ITCZ AUG 5

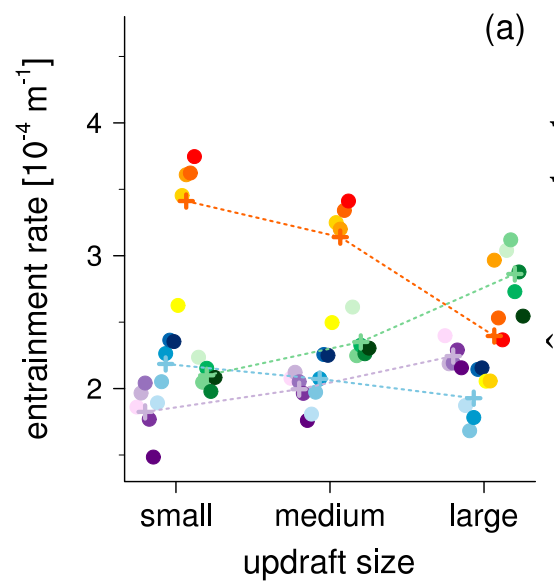

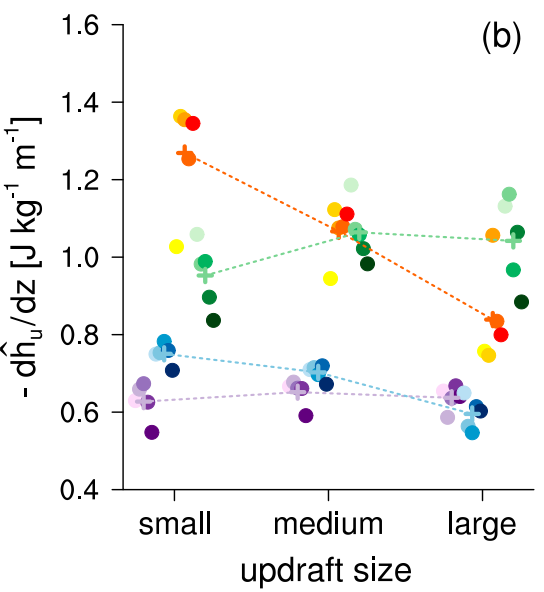

West Africa 1

West Africa 2

- West Africa 3

West Africa 4

West Africa 5

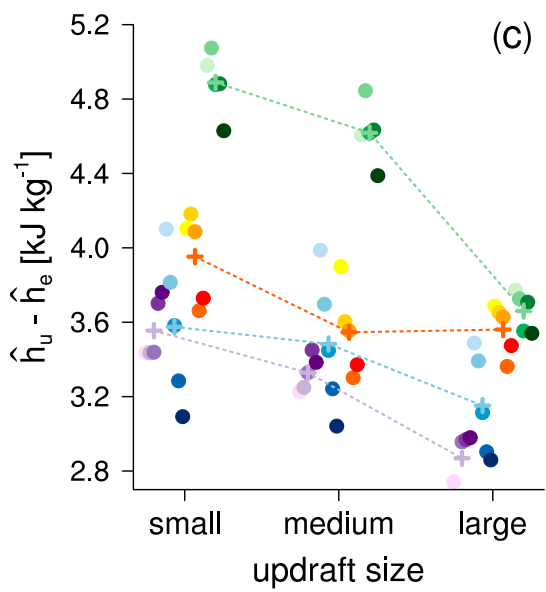

FIG. 11. (a) Vertical averages $(600-800 \mathrm{hPa})$ of bulk entrainment rates, (b) change of updraft frozen moist static energy with height, and (c) frozen moist static energy difference between updraft and $10 \mathrm{~km}$ neighborhood, ordered by updraft size as in Fig. 7, but in the different tropical regions. Subdomains are numbered from west to east. The crosses represent the mean value, averaged over all subdomains for each region and updraft size category.

when convection grows deeper (over land), which was artificially tested in Hohenegger and Stevens (2013), and which is in agreement with LES studies (e.g., Dauhut et al. 2016). Figure 13 shows that a time-dependent entrainment rate is in line with our findings as well: entrainment rates are weak in the afternoon over land and in the early morning over ocean, so at times of day when deep convection is expected to be very active. However, even though the time of the lowest entrainment rate coincides with the diurnal precipitation maximum over Amazonia and all ocean regions, this is not the case over West Africa, where the diurnal precipitation maximum occurs during the night (not shown), again indicating that mechanisms are more complicated over West Africa. Also note that at all times of day, entrainment rates are higher over West Africa than over the other regions, making the dependence on the diurnal cycle a dependency of less importance.

\section{Summary and conclusions}

In this study we used a bulk approach to estimate bulk entrainment rates for deep convection in five tropical regions, which are subdomains of the convection-permitting NARVAL simulations: the West Atlantic (both August and December), the Atlantic ITCZ (December), the Atlantic ITCZ (August),
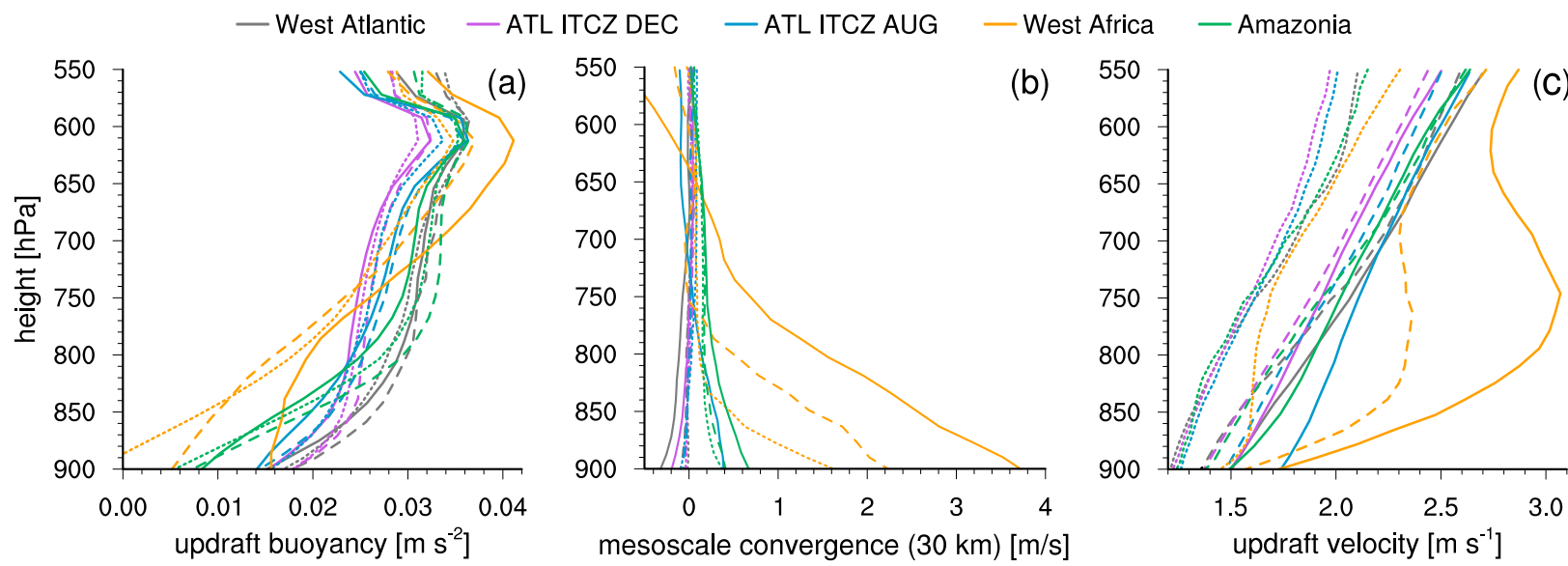

FIG. 12. Vertical profiles of (a) updraft buoyancy relative to the $10 \mathrm{~km}$ neighborhood, (b) mesoscale convergence in $30 \mathrm{~km}$ distance from each updraft grid point, averaged over the longitudinal and latitudinal direction, and (c) updraft velocity in the different tropical regions. Dotted lines indicate the first tercile of the updraft size distribution, dashed lines indicate the second tercile, and solid lines indicate the third tercile. 


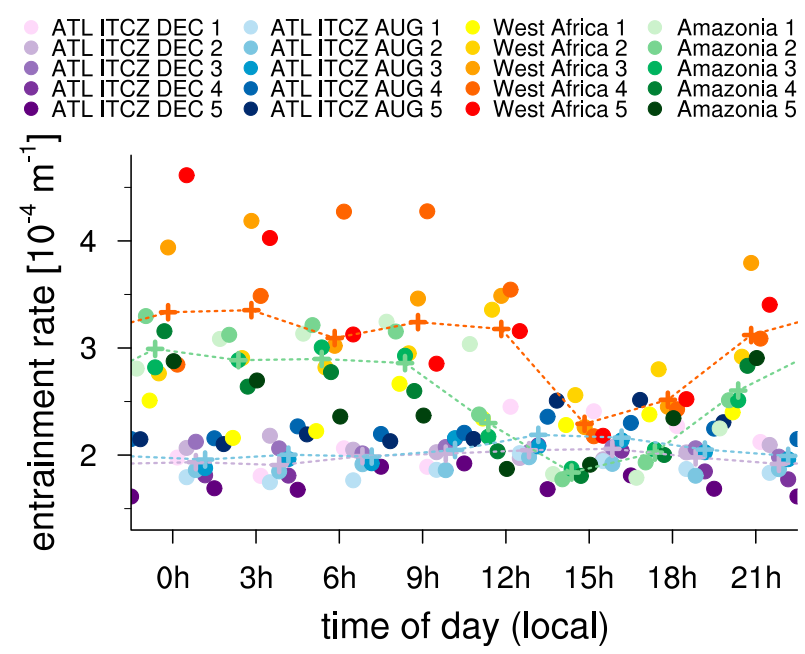

FIG. 13. Vertical averages $(600-800 \mathrm{hPa})$ of bulk entrainment rates with respect to the local time of the day, in the different tropical regions. Subdomains are numbered from west to east. The crosses represent the mean value, averaged over all subdomains for each region and local time.

Amazonia (December), and West Africa (August). The goal of the study was to investigate variations in entrainment rates across regions and their dependency on environmental conditions. A special focus was on the dependency between entrainment rate and static stability, humidity, TKE, and convective aggregation, all factors that have been mentioned in previous (mostly idealized) studies to affect entrainment rate. We estimated bulk entrainment rates using the conserved variable frozen moist static energy and a bulk approach (Betts 1975). The disadvantage of using a bulk approach to estimate entrainment rates is that results are only trustworthy within the height range that the majority of updrafts penetrate through, which in our study is between 800 and $600 \mathrm{hPa}$. However, the advantage of using a bulk approach is that bulk approaches are also used in most convection schemes, allowing for an easy comparison to such parameterizations.

We found that entrainment rates are higher over land (West Africa and Amazonia) than over ocean (West Atlantic and Atlantic ITCZ). This is true at all times of day except in the afternoon, when convective activity is strongest over land. Over Amazonia, entrainment rates are generally higher than over ocean because shallow convection increases the bulk entrainment rate below $700 \mathrm{hPa}$, while entrainment rates above that level are similar to those over ocean. Over West Africa, entrainment rates are the highest of all considered regions because in this region deep convection forms in squall lines. The squall lines are associated with strong mesoscale convergence and high horizontal turbulence kinetic energy. Over the ocean, where squall lines are mostly absent, entrainment rates are generally smaller because horizontal turbulence kinetic energy is weaker. Updrafts are less intense and their velocities scale with updraft buoyancy, indicating that updraft velocity is primarily controlled by thermodynamic effects. Over the West Atlantic, the regionally averaged bulk entrainment rates are slightly smaller than over the Atlantic ITCZ region in August and December, but differences are smaller than the differences between entrainment rates over land and over ocean.

In fact, with the exception of West Africa, regionally averaged entrainment rates differ less than entrainment rates within each region, subsampled with respect to different environmental conditions. The dependence on static stability is opposite over land and ocean, entrainment rates increase with static stability over ocean, while entrainment rates decrease with static stability over land. In addition, in contrast to convective parameterizations that make their entrainment rates larger in drier environments (e.g., Bechtold et al. 2008), entrainment rates strongly increase with environmental humidity in all regions. Such a dependency is consistent with buoyancy sorting arguments.

We also investigated the dependency of entrainment rate on convective organization. In RCE, aggregated convection is associated with higher entrainment rates than unaggregated convection (Becker et al. 2018). Here we were able to qualitatively reproduce this finding in the NARVAL simulations by using updraft size as a measure of convective aggregation: entrainment rates increase with updraft size in all regions except those that are dominated by squall lines (West Africa and, to a lesser degree, the Atlantic ITCZ region in August). Quantitatively, entrainment rate increases by 33\% for large relative to small updrafts over the West Atlantic, which is the region with the strongest dependency of entrainment rate on updraft size. This is also the region that most closely resembles RCE conditions. Moreover, in accordance with the RCE results, aggregated (large) updrafts are surrounded by a stronger moist shell, meaning that entrainment efficacy is reduced. However, this effect is less strong than in RCE and can only roughly balance the higher entrainment rates, with the consequence that, overall, the reduction of updraft buoyancy through entrainment does not change much with convective aggregation in the NARVAL simulations.

With respect to parameterization development, some of the isolated dependencies are in line with entrainment relationships used in convective parameterizations. For example, entrainment rates decrease with height and entrainment rates are larger for shallow convection than for deep convection. But other dependencies are also opposite to what is assumed in convective parameterizations. For example, entrainment rates increase with environmental humidity, and unlike in Gregory (2001), the region with the highest updraft velocities (West Africa) also has the highest entrainment rates. In analogy to parameterizations, where the properties of the entrained air depend on the grid spacing, some of our results may also depend on the chosen radius around updrafts that is used to estimate the properties of entrained air, in particular with respect to the moist shell. As the processes that govern convection, and entrainment rate in particular, strongly differ across the analyzed regions, we were unable to identify a single variable that entrainment rates are most sensitive to. Thus, we conclude that it will remain very challenging to develop an accurate parameterization of convection that is valid across a wider range of convective phenomena. This speaks for the use of alternate approaches, such as machine learning (e.g., Gentine et al. 2018; O'Gorman and Dwyer 2018) or global storm-resolving simulations (e.g., Stevens et al. 2019). 
Acknowledgments. The research was supported by the Max Planck Society for the Advancement of Science. Computing resources were provided by the German Climate Computing Center (DKRZ), Hamburg. The authors thank the internal reviewer Thibaut Dauhut and three external anonymous reviewers for their thoughtful and helpful comments to the manuscript.

Data availability statement. The NARVAL simulations are documented in Klocke et al. (2017). Secondary data and scripts used in the analysis, as well as other supplementary information that may be useful to reproduce the authors' work, are archived by the Max Planck Institute for Meteorology and can be obtained by contacting publications@mpimet.mpg.de.

\section{REFERENCES}

Baldauf, M., A. Seifert, J. Förstner, D. Majewski, M. Raschendorfer, and T. Reinhardt, 2011: Operational convective-scale numerical weather prediction with the COSMO model: Description and sensitivities. Mon. Wea. Rev., 139, 3887-3905, https://doi.org/ 10.1175/MWR-D-10-05013.1.

Bechtold, P., M. Köhler, T. Jung, F. Doblas-Reyes, M. Leutbecher, M. J. Rodwell, F. Vitart, and G. Balsamo, 2008: Advances in simulating atmospheric variability with the ECMWF model: From synoptic to decadal time-scales. Quart. J. Roy. Meteor. Soc., 134, 1337-1351, https://doi.org/10.1002/qj.289.

Becker, T., C. S. Bretherton, C. Hohenegger, and B. Stevens, 2018: Estimating bulk entrainment with unaggregated and aggregated convection. Geophys. Res. Lett., 45, 455-462, https:// doi.org/10.1002/2017GL076640.

Betts, A. K., 1975: Parametric interpretation of trade-wind cumulus budget studies. J. Atmos. Sci., 32, 1934-1945, https://doi.org/ 10.1175/1520-0469(1975)032<1934:PIOTWC>2.0.CO;2.

Böing, S. J., A. P. Siebesma, J. D. Korpershoek, and H. J. J. Jonker, 2012: Detrainment in deep convection. Geophys. Res. Lett., 39, L20816, https://doi.org/10.1029/2012GL053735.

Bretherton, C. S., and P. K. Smolarkiewicz, 1989: Gravity waves, compensating subsidence and detrainment around cumulus clouds. J. Atmos. Sci., 46, 740-759, https://doi.org/10.1175/ 1520-0469(1989)046<0740:GWCSAD>2.0.CO;2.

Collins, M., B. B. B. Booth, B. Bhaskaran, G. R. Harris, J. M. Murphy, D. M. H. Sexton, and M. J. Webb, 2011: Climate model errors, feedbacks and forcings: A comparison of perturbed physics and multi-model ensembles. Climate Dyn., 36, 1737-1766, https://doi.org/10.1007/s00382-010-0808-0.

Couvreux, F., F. Hourdin, and C. Rio, 2010: Resolved versus parametrized boundary-layer plumes. Part I: A parametrizationoriented conditional sampling in large-eddy simulations. Bound.-Layer Meteor., 134, 441-458, https://doi.org/10.1007/ s10546-009-9456-5.

Dauhut, T., J.-P. Chaboureau, J. Escobar, and P. Mascart, 2016: Giga-LES of Hector the Convector and its two tallest updrafts up to the stratosphere. J. Atmos. Sci., 73, 5041-5060, https:// doi.org/10.1175/JAS-D-16-0083.1.

_ _ _ P. Mascart, and O. Pauluis, 2017: The atmospheric overturning induced by Hector the Convector. J. Atmos. Sci., 74, 3271-3284, https://doi.org/10.1175/JAS-D-17-0035.1.

de Rooy, W. C., and Coauthors, 2013: Entrainment and detrainment in cumulus convection: An overview. Quart. J. Roy. Meteor. Soc., 139, 1-19, https://doi.org/10.1002/qj.1959.

Del Genio, A. D., and J. Wu, 2010: The role of entrainment in the diurnal cycle of continental convection. J. Climate, 23, 27222738, https://doi.org/10.1175/2009JCLI3340.1.
Derbyshire, S. H., I. Beau, P. Bechtold, J.-Y. Grandpeix, J.-M. Piriou, J.-L. Redelsperger, and P. M. M. Soares, 2004: Sensitivity of moist convection to environmental humidity. Quart. J. Roy. Meteor. Soc., 130, 3055-3079, https://doi.org/ 10.1256/qj.03.130.

—, A. V. Maidens, S. F. Milton, R. A. Stratton, and M. R. Willett, 2011: Adaptive detrainment in a convective parametrization. Quart. J. Roy. Meteor. Soc., 137, 1856-1871, https://doi.org/ 10.1002/qj.875.

Doswell, C. A., and E. N. Rasmussen, 1994: The effect of neglecting the virtual temperature correction on CAPE calculations. Wea. Forecasting, 9, 625-629, https://doi.org/10.1175/15200434(1994)009<0625:TEONTV>2.0.CO;2.

Fiedler, S., and Coauthors, 2020: Simulated tropical precipitation assessed across three major phases of the Coupled Model Intercomparison Project (CMIP). Mon. Wea. Rev., 148, 36533680, https://doi.org/10.1175/MWR-D-19-0404.1.

Gentine, P., M. Pritchard, S. Rasp, G. Reinaudi, and G. Yacalis, 2018: Could machine learning break the convection parameterization deadlock? Geophys. Res. Lett., 45, 5742-5751, https://doi.org/10.1029/2018GL078202.

Gregory, D., 2001: Estimation of entrainment rate in simple models of convective clouds. Quart. J. Roy. Meteor. Soc., 127, 53-72, https://doi.org/10.1002/qj.49712757104.

Hawkins, E., and R. Sutton, 2011: The potential to narrow uncertainty in projections of regional precipitation change. Climate Dyn., 37, 407-418, https://doi.org/10.1007/s00382-010-0810-6.

Hohenegger, C., and C. S. Bretherton, 2011: Simulating deep convection with a shallow convection scheme. Atmos. Chem. Phys., 11, 10 389-10 406, https://doi.org/10.5194/acp11-10389-2011.

- and B. Stevens, 2013: Preconditioning deep convection with cumulus congestus. J. Atmos. Sci., 70, 448-464, https://doi.org/ 10.1175/JAS-D-12-089.1.

Khairoutdinov, M., and D. Randall, 2006: High-resolution simulation of shallow-to-deep convection transition over land. J. Atmos. Sci., 63, 3421-3436, https://doi.org/10.1175/JAS3810.1.

Klepp, C., F. Ament, S. Bakan, L. Hirsch, and B. Stevens, 2015: NARVAL campaign report. Max Planck Institute for Meteorology Tech. Rep. 164, 218 pp.

Klocke, D., M. Brueck, C. Hohenegger, and B. Stevens, 2017: Rediscovery of the doldrums in storm-resolving simulations over the tropical Atlantic. Nat. Geosci., 10, 891-896, https:// doi.org/10.1038/s41561-017-0005-4.

Knight, C. G., and Coauthors, 2007: Association of parameter, software, and hardware variation with large-scale behavior across 57,000 climate models. Proc. Natl. Acad. Sci. USA, 104, 12 259-12 264, https://doi.org/10.1073/pnas.0608144104.

Kuang, Z., and C. S. Bretherton, 2006: A mass-flux scheme view of a high-resolution simulation of a transition from shallow to deep cumulus convection. J. Atmos. Sci., 63, 1895-1909, https://doi.org/10.1175/JAS3723.1.

Lin, C., and A. Arakawa, 1997: The macroscopic entrainment processes of simulated cumulus ensemble. Part II: Testing the entraining-plume model. J. Atmos. Sci., 54, 1044-1053, https:// doi.org/10.1175/1520-0469(1997)054<1044:TMEPOS>2.0.CO;2.

Lin, Y.-L., R. D. Farley, and H. D. Orville, 1983: Bulk parameterization of the snow field in a cloud model. J. Climate Appl. Meteor., 22, 1065-1092, https://doi.org/10.1175/1520-0450(1983) 022<1065:BPOTSF $>2.0 . C O ; 2$.

Lu, C., Y. Liu, G. J. Zhang, X. Wu, S. Endo, L. Cao, Y. Li, and X. Guo, 2016: Improving parameterization of entrainment rate for shallow convection with aircraft measurements and 
large-eddy simulation. J. Atmos. Sci., 73, 761-773, https:// doi.org/10.1175/JAS-D-15-0050.1.

__ , and Coauthors, 2018: Observational relationship between entrainment rate and environmental relative humidity and implications for convection parameterization. Geophys. Res. Lett., 45, 13 495-13 504, https://doi.org/10.1029/2018GL080264.

Mlawer, E. J., S. J. Taubman, P. D. Brown, M. J. Iacono, and S. A. Clough, 1997: Radiative transfer for inhomogeneous atmospheres: RRTM, a validated correlated-k model for the longwave. J. Geophys. Res., 102, 16 663-16 682, https://doi.org/ 10.1029/97JD00237.

Morton, B. R., G. I. Taylor, and J. S. Turner, 1956: Turbulent gravitational convection from maintained and instantaneous sources. Proc. Roy. Soc. London, 234A, 1-23, https://doi.org/ 10.1098/rspa.1956.0011.

Neggers, R. A. J., A. P. Siebesma, and H. J. J. Jonker, 2002: A multiparcel model for shallow cumulus convection. J. Atmos. Sci., 59, 1655-1668, https://doi.org/10.1175/1520-0469(2002) 059<1655:AMMFSC $>2.0$. CO;2.

O'Gorman, P. A., and J. G. Dwyer, 2018: Using machine learning to parameterize moist convection: Potential for modeling of climate, climate change, and extreme events. J. Adv. Model. Earth Syst., 10, 2548-2563, https://doi.org/10.1029/2018MS001351.

Raschendorfer, M., 2001: The new turbulence parameterization of LM. COSMO Newsletter, No. 1, Consortium for Small-Scale Modeling, Offenbach, Germany, 89-97, https://www.cosmo-model.org/.

Romps, D. M., 2010: A direct measure of entrainment. J. Atmos. Sci., 67, 1908-1927, https://doi.org/10.1175/2010JAS3371.1.

- and Z. Kuang, 2011: A transilient matrix for moist convection. J. Atmos. Sci., 68, 2009-2025, https://doi.org/10.1175/ 2011JAS3712.1.
Senf, F., D. Klocke, and M. Brueck, 2018: Size-resolved evaluation of simulated deep tropical convection. Mon. Wea. Rev., 146, 2161-2182, https://doi.org/10.1175/MWR-D-170378.1.

Siebesma, A. P., 1996: On the mass flux approach for atmospheric convection. Proc. Workshop on New Insights and Approaches to Convective Parametrization, Reading, United Kingdom, ECMWF, 25-57.

Stevens, B., and S. Bony, 2013: What are climate models missing? Science, 340, 1053-1054, https://doi.org/10.1126/science.1237554.

—, and Coauthors, 2013: Atmospheric component of the MPI-M Earth System Model: ECHAM6. J. Adv. Model. Earth Syst., 5, 146-172, https://doi.org/10.1002/jame.20015.

—, and Coauthors, 2016: The Barbados cloud observatory: Anchoring investigations of clouds and circulation on the edge of the ITCZ. Bull. Amer. Meteor. Soc., 97, 787-801, https:// doi.org/10.1175/BAMS-D-14-00247.1.

—_ , and Coauthors, 2019: DYAMOND: The DYnamics of the Atmospheric general circulation Modeled On Nonhydrostatic Domains. Prog. Earth Planet. Sci., 6, 61, https:// doi.org/10.1186/s40645-019-0304-z.

— , and Coauthors, 2020: The added value of large-eddy and storm-resolving models for simulating clouds and precipitation. J. Meteor. Soc. Japan, 98, 395-435, https://doi.org/ 10.2151/jmsj.2020-021.

Taylor, G. R., and M. B. Baker, 1991: Entrainment and detrainment in cumulus clouds. J. Atmos. Sci., 48, 112-121, https://doi.org/ 10.1175/1520-0469(1991)048<0112:EADICC >2.0.CO;2.

Turner, J. S., 1963: The motion of buoyant elements in turbulent surroundings. J. Fluid Mech., 16, 1-16, https://doi.org/10.1017/ S0022112063000549. 